Inter-organizational collaboration challenges and preconditions in industrial engineering projects

\begin{tabular}{|r|l|}
\hline Journal: & International Journal of Managing Projects in Business \\
\hline Manuscript ID & IJMPB-10-2019-0250.R1 \\
\hline Manuscript Type: & Research Paper \\
\hline Keywords: & Collaboration, Engineering Projects, Inter-organizational Projects \\
\hline \multicolumn{2}{l}{} \\
\end{tabular}




\title{
Inter-organizational collaboration challenges and preconditions in industrial engineering projects
}

\begin{abstract}
Purpose - The purpose of this paper is to achieve an understanding of the challenges and preconditions for inter-organizational collaborative project practices in industrial engineering projects. A framework for identifying the challenges and preconditions for inter-organizational collaboration is presented.
\end{abstract}

Design/methodology/approach - The adopted research method is qualitative, and empirical data were collected from the industrial engineering project sector in Finland. The literature related to industrial engineering projects and inter-organizational collaborative project management practices is summarized, informing the qualitative design of the study.

Findings - By analyzing empirical data from industrial engineering projects, the challenges for interorganizational collaboration are identified in each industrial engineering project stage. A framework of preconditions for inter-organizational collaboration is identified, in which investors are advised to pay attention when deciding on the use of collaborative project management methods.

Practical implications - The findings of this study help practitioners deal effectively with mechanisms aimed at fostering and hindering inter-organizational collaborative practices. The identified preconditions for interorganizational collaboration provide support for decision-making in every phase of an engineering project and can be used as guidelines throughout the process.

Originality/value - Inter-organizational collaborative project management practices have recently been attracting attention in the industrial engineering project setting. This research is an attempt to identify the underlying forces supporting and preventing inter-organizational collaboration in industrial engineering projects. This study offers a framework that can help academics and project management practitioners deal with the challenges affecting inter-organizational collaboration at each project stage and consider preconditions for inter-organizational collaboration in industrial engineering project settings.

Keywords Inter-organizational collaboration, Industrial engineering project, Inter-organizational project

Paper type Research paper

\section{Introduction}

Large engineering projects, or industrial engineering projects, are massive, indivisible, and long-term artifacts, with effects that are felt over many years (Miller and Lessard, 2000). Demand for interorganizational collaboration exists in project-based industries, where competition is intense and work is increasingly complex (Dietrich et al., 2010; Martinsuo and Ahola, 2010). Inter-organizational collaboration between different actors in project-based industries can be viewed as a means for reaching organizational goals and as the key success factor (Aapaoja et al., 2013; Bedwell et al., 2012; Dietrich et al., 2010). In general, industrial engineering projects provide a context for the development of new forms of inter-organizational collaboration (Miller and Lessard, 2000). However, particularly in industrial project settings, traditional lumpsum contracting predominates over collaborative models (Merrow, 2011). Nevertheless, it has been advocated that the contractual form does not directly affect project performance, but rather it influences project collaboration and team working quality (Suprapto et al., 2016). 
Therefore, partnering, alliances, and incentive contracts do not necessarily directly lead to optimal project performance, but rather they help identify positive performance through relational attitudes and team working quality (Suprapto et al., 2016). Furthermore, it has been found that the quality of owner-contractor collaboration in particular can improve project performance (Suprapto et al., 2016). The rationale behind inter-organizational collaboration in projects concerns the project members' ability to co-learn, understand one another's perspectives, and build social capital, which form the project asset, aimed at improving project outcomes (Walker and Lloyd-Walker, 2015), and collaborative learning, which is linked to project performance (Manley and Chen, 2017). In project alliancing, inter-organizational collaboration is developed through legal and obligatory requirements framework (Lloyd-Walker et al., 2014); in partnering, interorganizational collaboration is achieved through management approach (Aarseth et al. 2012), and, in integrated project deliveries, it is created through early integration of key partners and a contractual agreement (Lahdenperä, 2012).

Collaboration, in general, may take many forms and has been conceptualized in various ways in different disciplines (Bedwell et al., 2012). In order to tackle the ambiguities related to the collaboration concept, Bedwell et al. (2012) presented an integrated conceptualization, defining collaboration as 'an evolving process whereby two or more social entities actively and reciprocally engage in joint activities aimed at achieving at least one shared goal' (Bedwell et al., 2012, p. 130). What is important to note from the definition is that collaboration should be viewed as a process, and that it can take place at various levels including individuals, teams, organizations or even industries. In this paper, the focus is on collaboration between organizations engaged in a project. Inter-organizational collaboration is, however, also affected by the collaborative behaviors and activities of individuals and teams in projects. As time and dynamics are of high importance in temporary organization contexts, inter-organizational collaboration can be viewed as a relationship process between the owner and key stakeholders (Aaltonen and Turkulainen, 2018; Grabher, 2002). This process may include diverse collaborative elements and practices over the different lifecycle stages of a project.

As noted, several relatively similar project delivery arrangements that facilitate inter-organizational collaboration exist, such as project alliance, integrated project delivery, project partnering (Aarseth et al. 2012; Lahdenperä, 2012), relational contracting, supply chain management, integrated team working (Suprapto et al., 2015), and early contractor involvement (Chen et al., 2018). The common characteristics and constituents of inter-organizational collaborative relationships in projects include early involvement of key parties, transparent finances, shared risk and reward, joint decision-making, and collaborative multiparty agreement to varying degrees (Lahdenperä, 2012). Furthermore, the salient features of interorganizational collaboration are cooperative culture, administrative consistency, commercial unity, team formation, teamwork premises, planning emphasis, and operational procedures (Lahdenperä, 2012). In project alliances, close collaboration can be pursued through joint contract, joint responsibility, joint organization, joint risk-bearing, information accessibility, and unanimous decision-making (Lahdenperä, 2017). It is also important to note that Inter-organizational collaboration is shaped by both past experiences and potential future collaboration (Grabher, 2002). Moreover, episodic inter-organizational project collaboration has the potential to turn into enduring project networks (Grabher, 2002).

Project-related and managerial antecedents remain under-researched respecting inter-organizational collaboration in project networks (Oraee et al., 2017), and further research is required to understand how temporary dynamics of projects affect the inter-organizational collaborative activities among organizations (Oliveira and Lumineau, 2017). The question is how trust-based collaborative relationships can be realized, and research is therefore required to understand how to achieve inter-organizational collaboration over the project lifecycle (Manu et al., 2015) and what kinds of pre-conditions may support this process. Further, in practice, it has proven problematic to maintain and foster inter-organizational collaboration within companies and among actors who represent various disciplines and are geographically dispersed (Aarseth, 2014; Aarseth and Sorhaug, 2009; Oraee et al., 2017). In this paper, the challenges of inter-organizational 
collaboration are understood as factors or elements which may inhibit the development of interorganizational collaboration. With regard to such challenges, particularly the mindset challenges, which relate to the attitudes and taken-for-granted values of individuals and organizations have been highlighted (Aarseth,2014; Aarseth and Sorhaug, 2009). More research is, however, needed on how inter-organizational collaboration challenges unfold during the different stages of the project lifecycle and what kinds of preconditions may facilitate proper collaboration among project participants in the context of industrial engineering projects.

The aim of this study was to identify the challenges of inter-organizational collaboration in an industry that comprises project networks and traditionally operates in environments that lack drivers for collaboration: industrial engineering projects. Using a qualitative approach, an empirical investigation was conducted among organizations undertaking industrial engineering projects in Finland. Furthermore, the study intended to extend the literature by empirically identifying the factors that appear as preconditions for inter-organizational collaboration in industrial engineering project settings. This study was guided by the following research questions:

$R Q 1$. How is inter-organizational collaboration in industrial engineering projects defined in the literature?

$R Q 2$. What are the challenges of inter-organizational collaboration in industrial engineering projects?

$R Q 3$. What are the preconditions for inter-organizational collaboration in industrial engineering projects?

\section{Theoretical background}

The concept of collaboration

Inter-organizational collaboration and collaboration in general have been defined in multiple ways in different disciplines. The problem of multiple definitions has led to confusion and is one of the reasons why it is very challenging to identify the determinants of collaboration or measure and assess collaboration based on jointly agreed indicators (Bedwell et al., 2012). There exists, however, consensus on that collaborative processes among organizations take place because they facilitate the accomplishment of organizational goals and performance (Aapaoja et al., 2013; Dietrich et al., 2010). Consequently, actors engage in collaborative interactions and activities in order to improve the competitive advantage of firms. While the outcomes and goals of collaboration are relatively clear, the elements that form collaboration practically and conceptually are much more ambiguous. The lack of a joint and unified understanding of the attitudes, cognitions, practices and behaviors that constitute collaboration has challenged the use and measurement of collaboration in prior research. Yet, some attempts to integrate the elements and understanding of collaboration across disciplines have taken place. Based on an extensive literature review Bedwell et al. (2012) defined collaboration as a process that evolves and in which organizations reciprocally engage in joint activities aimed at achieving at least one shared goal. This notion of collaboration emphasizes the processual nature of collaboration instead of viewing it as an outcome. Collaboration can therefore be seen to involve relationship-based arrangements that may change over time and, in the context of projects, over their lifecycle (Aaltonen and Turkulainen, 2018). Chiocchio et al. (2012) conceptualized collaboration at the team level showing how collaborative work may predict team performance. However, in practice, establishing environments and contexts that facilitate collaboration is challenging (Aarseth, 2015). To overcome the practical challenges in implementing collaborative practices ISO 44001 Collaborative Business Relationship Management System standard, which addresses collaborative business relationships, was developed and launched in 2017 (Chakkol et al., 2018).

Concepts similar to collaboration, such as partnering have also been discussed in project research (Børve et al., 2017). Indeed, partnering, defined as 'relationship strategy whereby a project owner integrates contractors and other major contributors into the project' shares similar features with the concept of collaboration, as it highlights commitment to mutual project objectives, collaborative problem solving and a 
joint governance structure in facilitating collaborative relationships and trust (Børve et al., 2017, p. 694). Partnering research, however, tends to adopt more explicitly the perspective of the project owner (Walker and Lloyd-Walker (2015), and highlight relationship-based procurement aspects. Factors that are seen to facilitate partnering success relate to participant selection, task clarification and partnering means, which consist of partnering attitude, collaborative culture, holistic perspective and accurate handover (Nevstad et al., 2018). Overall, research on collaboration and partnering has shown that the most significant factors of project delivery performance are communication, alignment of interest and objectives, team working, trust and gain/pain sharing. Projects which implement these practices in their supply chains are better off (Mesa et al., 2016). Also Chakkol et al.'s (2018) study shows how the formalization of collaboration practices through partnering and collaboration standards between clients and contractors in complex projects facilitates co-operation among the parties.

\section{Inter-organizational collaboration in projects}

Collaboration between organizations i.e. inter-organizational collaboration has been approached from diverse perspectives in project research. Inter-organizational collaboration is often linked to behavioral drivers (Lloyd-Walker et al., 2014), and relational attitudes such as trust, common vision and objectives, open and honest communication, no-blame culture, social interaction, and senior management commitment between organizations (Suprapto et al., 2015). Haaskjold et al. (2020) postulate that improved interorganizational collaboration between project contractors and clients reduces transaction costs. In their study, particularly the quality of communication, project uncertainty, owner's organizational efficiency, change orders and trust were seen to influence most significantly the level of collaboration and hence transaction costs. Creating such conditions requires, however, a certain level of maturity from the collaborating organizations (Haaskjold et al., 2020).

Classifying inter-organizational collaboration research in projects can be done in various ways, but as the collaboration activities take place in the project system, Browning et al.'s (2006) framework, which models complex projects and their development as systems was adopted. Browning et al.'s (2006) classification of five project systems (i.e., goal, organization, process, tool, and product) is, hence, the framework around which the concept of inter-organizational collaboration was organized in this study. In this model, the process, that is the work done, is treated as a system that can be engineered and induced to facilitate the development of product systems that are the desired results of the project. The organization system, in turn, consists of the individuals, teams or organizational units that have been assigned to do the work, which produces the product system, while the tool system is composed of the technologies that people use in their work to produce the product. These four elements of product, process, organization and tool systems are operating in the context of goals or requirements forming the goal system. Not only does this sort of classification of inter-organizational collaboration reveal behavioral and relational aspects linked to collaboration, but also illustrates how various elements of inter-organizational collaboration relate to one another and the project system as a whole. Each of the systems may then constrain or enable the other systems. The framework therefore enables the development of a single model to support the planning of inter-organizational collaboration systems. Following the five project systems model (Browning et al., 2006), a compilation of prior empirical viewpoints on inter-organizational collaboration in projects is presented in Table I.

In the context of projects inter-organizational collaboration is created through common goals. These may be achieved, for example, through contracts (Suprapto et al., 2015), incentivization schemes (Dietrich et al., 2010; Walker et al., 2017), risk and reward sharing (Chen et al., 2018; Lahdenperä, 2012), or decision-making by consensus (Walker et al., 2017). However, prior literature has suggested that contracts may be very important but not always an essential precondition for inter-organizational collaboration.

An organizational system in a project consists of people, teams, organizational units, etc., which undertake the work that is related to each other through mechanisms such as communication (Browning et al., 2006). 
The literature on inter-organizational collaboration stresses the importance of themes such as trust (Dietrich et al., 2010; Haaskhold et al., 2020), trust-control balance (Walker et al., 2017), relationship programs (Aaltonen and Turkulainen, 2018), culture of collaboration (Aarseth and Sorhaug, 2009) and focus on team formation (Lahdenperä, 2012; Oraee et al., 2017) or teamwork in general (Chen et al., 2018; Oraee et al., 2017; Suprapto et al., 2015). Yet, focusing too much on relationship development and embeddedness may also lead to the realizations of the dark sides of collaborative relationships. When organizations become too dependent and close with each other, the inter-organizational collaborative relationships may also act as a risk source of their own (Artto et al., 2008).

Furthermore, the process of inter-organizational project collaboration seems to be strongly associated with integration (Chen et al., 2018; Suprapto et al., 2015; Walker et al., 2017). This is in line with the notion of megaprojects, where integration is a critical element that helps participating organizations cooperate more effectively (Teerikangas and Geraldi, 2015). In addition, the empirical literature states that the tools for inter-organizational collaboration are based on co-location, physical or virtual (Aaltonen and Turkulainen, 2018; Gustavsson and Gohary, 2012; Lahdenperä, 2012; Walker et al., 2017). However, there are limited indications that the prior literature is focused on products relating to inter-organizational collaboration. 


\section{Inter-organizational collaboration and project governance}

Projects are embedded in organizations and industries but also in networks of inter-organizational relationships (DeFillippi and Sydow, 2016). Project network can either be interpreted as a single interorganizational project or a series of projects connected by inter-organizational relationships (DeFillippi and Sydow, 2016). Contrary to its parent organization alone, a project can be considered a powerful organizational actor that is able to contribute to the rules, followed by organizational actors who participate in the project (Ahola et al., 2014).

The following elements play a major role in the governance of a large project: contracts, procurement, communication, supplier networks management by project actors, risk management and sharing, work monitoring and coordination, and collaboration and developing practices between project actors (Ruuska et al., 2011). Furthermore, a project and project network can be governed through roles, responsibilities, routines, and relationships, where relationships refer to governance of social aspects (DeFillippi and Sydow, 2016).

Collaboration can be seen as one of the soft features of project governance (Walker and Lloyd-Walker, 2015). Moreover, the governance structure of collaborative projects comprises formal and informal mechanisms to facilitate the negotiation and execution of human capital transactions (Manley and Chen, 2017). Sophisticated collaborative governance structures apply both contractual and non-contractual governance mechanisms (Chen et al., 2018). However, flexibility and formality in inter-firm collaboration vary (Aagaard et al., 2014).

Project performance can be divided into tactical and strategic successes (Samset and Volden, 2016). Tactical performance refers to project management issues and typically means meeting short-term performance targets (Samset and Volden, 2016). In contrast, strategic performance refers to project governance issues and includes broader and long-term considerations of a project's impact on sustainability, relevance, and effectiveness throughout its life-span (Samset and Volden, 2016); the term sustainable project success may be applicable here (Walker and Lloyd-Walker, 2015).

\section{Inter-organizational collaboration in industrial engineering projects}

Most projects operate in turbulent and complex environments, and traditional project management is not suitable for such environments (Williams and Samset, 2010). A typical way of reducing risk and uncertainty in complex environments is through creating collaborative arrangements, with a view to sharing some of the risks and benefiting from pooled expertise (Dietrich et al., 2010). Indeed, project-based organization is a learning organization, in which learning is facilitated by social capital assets that project team members bring to the project through collaborative processes (Walker and Lloyd-Walker, 2015). Furthermore, in contrast to traditional approaches, governance regimes of megaprojects should be time-dependent and self-organizing, thus being able to transform the governance structure over time (Williams and Samset, 2010).

It has been argued that alliance contracting increases instability in project execution, when it comes to industrial engineering projects (Merrow, 2011). The main argument against alliancing in industrial engineering projects is that complex projects require a form of contracting that clearly indicates the scope of responsibility and accountability and the mechanism for conflict resolution (Merrow, 2011). Besides being understaffed and dealing with aggressive costs and schedule targets, when compared to traditional projects, a risk in alliancing is when no one takes responsibility (Merrow, 2011).

However, this view has been criticized for its lack of attention to the positive indirect effects of alliancing, partnering, and incentive contracts on project performance (Suprapto et al., 2016). In fact, contractual and non-contractual forms of governance complement rather than substitute each other, where more emphasis on the non-contractual form of governance has to be laid on contexts with high uncertainty, high asset specificity, and strategically important suppliers (Chen et al., 2018). Furthermore, contracts govern the relationships between organizations; however, they only influence how organizations collaborate (Oliveira and Lumineau, 2017). In general, it has been noted that excessive emphasis on economic incentives may 
distract project team members from their work (Suprapto et al., 2015). Contractual governance has been found to be effectively used only in moderation, and more emphasis should be on relationship-based modes of governance (DeFillippi and Sydow, 2016).

It has been suggested that collaboration may lead to reduced ambiguity for people and processes (Walker et al., 2017). Moreover, risk, uncertainty, and ambiguity can be managed efficiently through intimate and open collaboration between the project owner, the design, and the delivery teams (Walker et al., 2017). True collaboration is established through formal entities, and usually with a long-term focus (Aapaoja et al., 2013). Furthermore, as collaboration between project parties becomes more established over time, parties tend to collaborate more efficiently (Martinsuo and Ahola, 2010). Overall, collaboration can be seen as a way of dealing with fragmentation and lack of integration between project partners in order to improve project performance (Gustavsson and Gohary, 2012).

Furthermore, front-end phase of the projects, including project definition, and decisions made in these early stages have been identified as key for ensuring project strategic success (Samset and Volden, 2016). Well-executed and complete front-end loading phase restrains cost growth and schedule slippages, lowers the risk for operability failures, reduces changes during execution, and improves construction site safety (Merrow, 2011). However, in addition to proper front-end planning, continuous coordination and collaboration among the project participants are typically needed over the course of complex projects (Aagaard et al., 2014). Furthermore, the early involvement of project stakeholders leads to holistic value cocreation, whereas the possibilities for affecting project success are seen to be greatest in the early stages of projects (Aapaoja et al., 2013).

\section{Research method and data}

This study aims at recognizing the challenges and preconditions for inter-organizational collaboration in large-scale industrial project settings. The unit of analysis is an inter-organizational project network, which has the shadow of the past projects (Ligthart et al., 2016). Industrial engineering projects are unique, dedicated, and usually one-off products, with intensive interactions between sponsors and contractors (Miller and Lessard, 2000). These projects are a product of negotiated compromise, face varying pressures from stakeholder groups, are crafted over years, are exposed to political risks, face coherent regulatory framework, and include large, irreversible commitments (Miller and Lessard, 2000). These features of industrial engineering projects also apply to our empirical sample of projects.

\section{Empirical context}

The context of the empirical study is the industrial engineering project sector in Finland. The industrial engineering projects include technical design, equipment manufacturing, and assembly of the production line for the industrial process in question, to which the design and contracting and building the surrounding industrial facility can be added. Due to the global depression, arising from the 2008 financial crisis, there has been nearly a decade-long investment decline in industrial capital investments in Finland; however, since 2015, the investments have been significantly rising (Confederation of Finnish Industries, 2018). Probably due to the long economic recession and decline in industrial investments, the use of collaborative practices has not been widespread within the industry. However, there seems to be a growing need to elaborate these emerging management methods and their suitability for the industry, which is also a focus of this research work.

Companies selected for this study represent different hierarchy levels of the industry structure, ranging from $\mathrm{N}$-tier subcontractors to investors and owners. Seven companies (17 interviewees) had taken part in project alliances either as an alliance member or as an outside subcontractor. On the other hand, two companies ( 3 interviewees) had no alliance experience; however, they had taken part in engineering, procurement, construction management (EPCM) project or some forms of collaborative projects. Three companies ( 3 interviewees) had no experience of collaborative forms of procurement. Finding many projects 
that have a predecessor and a successor of some kind (DeFillippi and Sydow, 2016) is also applicable here, since most of the interviewed companies have cooperated in various industrial projects and are most likely to continue this trend in the future.

\section{Research strategy}

In light of the limited previous research regarding inter-organizational collaboration in industrial engineering projects, the method used in this study was qualitative (Seale et al. 2004). The qualitative research design was particularly suitable for our study, as we wanted to map the challenges and pre-conditions over the project lifecycle phases, and the qualitative approach enabled the withdrawal of rich and in-depth data of the studied phenomenon in its context. The approach of conducting the research involved theory generation, whereby inductive reasoning is a central concept (Ketokivi and Choi, 2014). However, the research strategy was not completely inductive, but has also abductive features, since the data were elaborated and the categories were created according to Browning et al. 's (2006) established framework. In addition, the challenges of inter-organizational collaboration were classified around project phases. The validity of the study was assured, following Yin (2003): using multiple sources of evidence, establishing a chain of evidence, and having the key informants read the study report through (Yin, 2003); external validity was assured using replication logic and reliability was assured following the case study logic (Yin, 2003).

\section{Data collection and analysis}

Data were collected through 12 semi-structured interviews, involving 23 interviewees. The supporting materials consisted of project reports, presentation materials, and public sources such as newspaper articles and websites. The interviewees were selected so that they represented the different salient actors in industrial engineering projects in a balanced manner. Furthermore, we aimed to select representatives from organizations that had a long track record and experience with regard to industrial engineering projects and who were also familiar with the collaborative project delivery arrangements and interested in their application in this context. The potential interviewees were also discussed with highly renowned professionals within the field as well as mapped in the actual interviews using a snowballing technique. Most of the interviews took place in the premises of the researched companies; two other interviews took place in a local chamber of commerce premises. In five of the interviews there were more than one interviewee present and the interview was conducted as a group interview. In these sessions the participants were posed with the same questions that were in the interview guide, but typically the interviewee who was most familiar with the topic answered first. Then after this, the other interviewees could still complement this answer. The interviewees were not, however, able to engage in a completely open discussion with each other on the topic, but the interviewers were facilitating and controlling the situation. Between two and four interviewers took part in each interview, of whom at least two were physically present during the interview. On a few occasions, the Skype ${ }^{\mathrm{TM}}$ was used. The interviews took place during March-May 2018 and lasted between 72 and 180 minutes. The interviews were recorded and transcribed; in addition, notes that had been taken during the interviews were also used. Table II presents information on the participating companies and the interviews.

The transcribed interviews were transferred to NVivo software for further coding. Initial coding organized the data according to the main themes, arising from the conversation. During the second round of coding, different challenges and preconditions as well as the influential actors in relation to different project stages were coded. This coding round followed the research questions RQ2 and RQ3. Finally, the preconditions for collaboration were organized according to Browning et al. 's (2006) framework, in a fashion following directed content analysis (Hsieh and Shannon, 2005). Browning et al.'s (2006) five systems model (goal, organization, process, tool, and product) was selected as a means to classify the pre-conditions because the model reveals well behavioral and relational aspects with regard to collaboration, but more importantly adopts a system level perspective for understanding inter-organizational collaboration. Furthermore, as prior research on inter-organizational collaboration was reviewed utilizing this framework, its use as a coding 
scheme in the empirical analysis, offered a possibility to compare the findings from the literature review with the empirical results.

The data collected in the interviews were compared and contrasted to avoid biases. Furthermore, the collected data were validated in two workshops, attended by the interviewees, participants from the researched organizations, and other industry representatives. The preliminary findings from the data were presented by the researchers; these in turn were validated and further developed in the workshops. The initial categories were built based on the coded data and were subsequently combined (see the following chapters).

$<$ INSERT TABLE II HERE>

\section{Results}

Table III summarizes the key challenges of collaboration in different project phases, identified by the interviewees during the interview sessions and therefore answers to RQ2. In general, the degree of experience of collaborative project practices varied among the researched organizations. Seven companies (17 interviewees) had taken part in project alliances, whereas three companies ( 3 interviewees) did not have any type of collaborative experience. Against this backdrop, there were indications, albeit not very evident, of both organizational and mindset-related challenges toward this new governance and operating model. However, we were also able to identify the preconditions for successful collaborative project implementation in industrial engineering project setting addressing hence RQ3. The respective challenges and preconditions are elaborated below.

\section{Challenges for collaboration in different project phases}

Gate 0: decision on the level of collaboration. The first identified phase in which the challenges emerged was early in the project where the decisions on the use of collaborative practices were optimally made. The empirical findings indicate that, in addition to the decision on the actual collaboration execution plan, the decision on the use of collaborative project practices should be made before the final investment decision. Our empirical findings suggest that investors may be unable to reach an internal consensus on collaboration, mainly because the collaborative practices may be unfit for the current processes and generate internal resistance within different departments; furthermore, investors' organizational culture may not support collaboration. If an investor has a lack of knowledge of collaborative project management, he/she will not have strong internal operating procedures for collaborative projects or required skilled personnel for such operations. This poses a challenge for the recruitment and organizational development activities; managers and project personnel should attain a requisite knowledge of organizational procedures and adjust their operations accordingly prior to the commencement of the project. Given the abovementioned challenges, an investor's goals for collaboration may be vague and hence hinder rational decision-making in relation to deploying collaborative practices. Moreover, it was brought up that investors may not be interested in investing additional time in collaborative contract creation or sharing intellectual property rights (IPR) of collaboratively devised solutions.

Pre-engineering. In the pre-engineering phase, general technological plans and choices are made. In this phase, one of the main challenges affecting collaboration is that the investor requires a large number of decisions to be locked before the development begins in the basic engineering phase. This leads to a situation where many of the benefits of collaboration may not be realized, since, as the interviewees reiterated, collaborative problem-solving is one of the key value-enhancing factors. According to our interviewees, in this phase, project organizations are keen on maintaining the old controversial project culture, which is 
characterized by the fact that common goals may not have been clearly formulated and agreed upon. Another challenge that the interviewees identified concerns the project parties' focus on the project itself rather than collaboratively ensuring the optimal ramp-up and lifecycle functions of the facility.

Investment. Empirical evidence indicates that there are difficulties in securing funding for the preengineering and design phases of industrial engineering projects. Funding bodies are more willing to allow funding for complete front-end loading plans that are ready for execution. However, there appears to be a dilemma, mainly because large engineering projects require extensive design and planning; thus, funding in the front end and the execution phases of the project is more likely to succeed (Merrow, 2011). Furthermore, compared to traditional project models, collaborative projects tend to be more costly at the beginning, which makes obtaining funding in the front end even more difficult, especially for relatively small investors; our interviewees also pointed out that funding difficulties in the front end may also lead to key experts leaving the project team. Funding bodies in their own right tend to favor projects that are able to gather funding from various organizations; this may also pose a challenge in the volatile design and planning phases. In addition, the local political environment affects funding bodies and their decision-making.

Basic engineering. In collaborative projects, this phase is often used as a special development phase. The main project parties already have contractual agreements, and design solutions are sought at a basic engineering level. The interviewees described it as very problematic when they did not receive design basic information from the process equipment manufacturers right at the beginning of the basic engineering phase, since it has a major role in facilitating the collaborative work. This follows Merrow's (2011) reasoning, in that the late arrival of Basic Data is one factor for limited success of the industrial project front end loading and of the project on the whole. This issue is further complicated when the investor delays as much as possible the decision on process equipment suppliers in the project.

Challenges associated with leadership and team building efforts greatly hinder collaborative work in basic engineering phase, whereas the interviewees recognized them as key components for successful collaboration. Furthermore, challenges may occur in collaborative space (Big Room) activities, such as lack of fostering and managing the activities, as identified by our interviewees, or in engaging key resources to operate full time or as much as needed in the Big Room. One of the motivational challenges concerns the issue of whether personal and organizational incentives help collaborative actions achieve the project targets; this was seen as one of the investor's success factors in contracting. It has to be noted that collaborative capabilities vary considerably among subcontractors, who may require some actions from investors (e.g., education). Coordinating communication about design solutions and changes in design between various subcontractors was also recognized as a challenge, whereas this challenge is also likely in the execution phase. In addition, the interviewees discussed the issues related to supply chain management. Since the delivery times of industrial components are very long, even up to one year, subcontractors have to pass the orders down the subcontracting chain as early as possible. This poses a challenge to collaboration and respective communication, mainly because subcontractors may not have much time to wait for collaborative solutions to emerge when they do not belong to the inner circle of the collaborating parties.

\section{Execution: detailed engineering}

One of the issues affecting project schedule is the late signing of the subcontracting contracts, since the subcontractors do not start their actual design work until the contract has been signed. Prior to that, according to the interviewees, only plans from previous projects are circulated, which form a poor basis for proper collaborative problem-solving and respective solutions.

Empirical study also revealed the challenges related to project culture. If the project culture is not strong enough, the project participants may lower work standards if they are not rigorously monitored. Moreover, if health and safety issues are based solely on fines and punishments, violations tend to be covered up instead of pointing out and correcting the emerging critical issues. In addition, cultural differences among project 
participants were seen as critical for the project culture, since the underlying rules and assumptions may differ considerably.

Finally, the interviewees pointed out the challenges of integration between project participants. Challenges of work planning among subcontractors exist, to which challenges in coordinating emerging issues between investors, contractors, and subcontractors can be added.

$<$ INSERT TABLE III HERE>

\section{Preconditions for collaboration}

The identified preconditions for inter-organizational collaboration in project setting, based on the empirical findings, were organized around Browning et al.'s (2006) five systems in a project (i.e., goal, organization, process, tool, and product) (see Figure 1). The detailed explanations of the empirical findings regarding preconditions for inter-organizational collaboration in each project system are presented in Table IV.

$<$ INSERT Figure 1 HERE >

According to the interviewees, one key precondition is to decide on the use of collaborative practices early in the project, before signing any contract. In this manner, the use and development of collaborative project practices can be taken into account from the very beginning of the project pre-engineering phase. Targets and responsibilities for collaboration must be determined and formulated into a bonus model. All the necessary collaborative bonus models and respective measures such as possible requirements for colocation should be negotiated during the contract creation process and added to the final contract. Targets, responsibilities, bonus model, and measures ought to be communicated to all the project parties concerned.

Furthermore, according to the empirical findings, not all the subcontractors are required nor are they willing to participate in the inner circle of collaboration. Nevertheless, one way to introduce collaborative elements for $\mathrm{N}$-tier subcontractors is referred to as target hour contracts, in which the scope and price of the delivery may vary depending on the pace in which the work proceeds. It is also important to visualize and discuss the targets of the project jointly with the subcontractors.

However, the decision on the use of collaborative project practices may not be easy in industrial engineering project settings. Obtaining investors' internal approval of the use of collaborative practices may be difficult, especially if the collaborative project management knowledge and skills have not been properly maintained within the organization among the investment projects. In addition, as a precondition, commitment on the wide-scale use of collaborative practices is required internally; this is how one of the interviewees chose to frame it: "I can assure you that our legal department would have had serious issues to accept a contract that uses the pronoun 'us' only." Therefore, communication and training, which facilitate the change of the mindsets and attitudes concerning the potential of inter-organizational collaboration should be offered.

Hence, as a precondition for project organization, building collaborative capabilities into an engineering project ought to take place both during projects and over projects. Early cross-disciplinary interaction between process equipment suppliers, construction contractors and designers should also be promoted. During projects, collaborative capability building efforts focus on recruitment of individuals with collaborative mindset, education and training, authentic leadership, trust and personal relationships, and the development of good project spirit. Leadership that promotes collaboration requires also significant commitments from 
the project manager, who is typically acting as the leading figure in building trust and co-operation. Collaborative capabilities over projects, as our empirical data suggest, are built through partnering early and especially among projects. Such collaborative relationships then also enable the contacting of potential key partners early during the project life-cycle.

One of the key preconditions for project processes are early integration and involvement of the project parties, including funding bodies, process equipment suppliers, construction contractors and designers, and low-tier subcontractors. This allows all the necessary information to be brought into the project as early as possible and to be utilized in various solutions from the early stages. Another precondition for collaboration is focus on innovation process and respective innovation process management with rewards. Empirical results indicate that very successful collaboration can be reached in this manner. What also needs to be considered is the realistic time window for executing the development phase. In industrial engineering projects this can also be a relative short period.

Project tools that support collaboration and operate as preconditions for collaboration encourage personal relationships, communication, collective work planning and problem-solving, and continuous improvement. Our interviewees emphasized the significance of collaborative project management techniques, such as collaborative space i.e. Big Room practices which enable regular face-to-face contacts or the Last Planner tool for collaborative scheduling. Also the importance of a joint document management system offering collaborative features was emphasized. One important factor pointed out in our empirical research was the creation of common rules for all project members, especially in regard to building site functions concerning health and safety issues and visualizing these in a clear manner. However, the ability and willingness to change the rules whenever proven inefficient were deemed equally important, illustrating flexibility. Investments in continuous improvement and learning practices such as regular reflection routines were also highlighted as an important means.

Finally, we were also able to discover a few inter-organizational collaboration preconditions for successful project products, which, in industrial engineering projects, may be a well-functioning factory; these included receiving design basic information from process machinery suppliers as early as possible, value for the investor, well-executed front-end loading phase, and pilot testing of process technology in a factory setting.

$<$ INSERT TABLE IV HERE>

\section{Discussion}

The empirical analysis identified challenges of and preconditions for inter-organizational collaboration in the different phases of industrial engineering projects. Indeed, the majority of the collaboration components related to goals, organization, processes and tools that were identified in the literature review (Table 1) were also brought up by the interviewees. In addition, new insights and discoveries that complement prior literature on inter-organizational collaboration in industrial engineering projects were also made. Particularly the insights related to the product component are new. The following discussion is formed around Browning et al.'s framework (2006) and the components of collaboration.

First, with regard to goals, the incentivization scheme for pain and gain sharing aiming at the alignment of goals among the actors, and the contractual arrangements supporting this, were a common theme resonating with prior research (Chen et al., 2017; Dietrich et al., 2010; Walker et al., 2017). Here, the interviewees highlighted that it would be beneficial if decisions on collaborative project practices were made before any contracts are signed. This perspective has been only limitedly addressed in prior literature. The 
use of collaborative practices may influence contractors' pricing norms and the content of the contracts, which are challenging to change later. Consequently, early introduction, communication and dialogue of the development of common goals and bonus models with each key stakeholder was considered as a practice that would facilitate inter-organizational collaboration in industrial engineering projects. This would also require new type of proactive, cross-disciplinary collaboration between the legal professionals, financiers, and representatives of the different engineering disciplines and suppliers.

Furthermore, our interviewees underlined the importance of determining clear targets for collaboration and the respective responsibilities which resonates with the literature highlighting the development of clear and precise risk and reward schemes (Chen et al., 2018; Suprapto et al., 2015). It needs to be noted that targets do not have to be determined at the contractual level; rather, each organization and especially investors have to have a clear view on what is pursued through using collaborative practices in project management. According to one of the interviewees, "the use of collaborative model has to start in the design [pre-engineering] phase. The target and the responsibilities have to be crystal clear... so that no one can come and say after two years of working that we did not mean this at all..." The development of clear targets puts emphasis on the capabilities of the investor (i.e. owner) in terms of establishing a clear vision for the project. Here, also the early engagement and dialogue with the suppliers is a necessity in order for the common understanding and commitment to mutual objectives to develop. The notion of owner's capabilities, maturity and role as an integrator in establishing a proper framework for the development of mutual project objectives has also been highlighted in prior partnering research (Børve et al., 2017; Haaskjold et al., 2020; Nevsta et al., 2018).

Furthermore, the importance of clearly and comprehensively communicating the bonus model and measures related to it was emphasized in the empirical data. The communication practices can be presented to the project personnel in as many details as possible. This was considered to be particularly important when building site personnel do not have a common language, although every employee needs to be aware of the key targets. The finding on the importance of communicating the joint objectives and the means and indicators for their measurement in an understandable manner lends support to a recent research by Haaskjold et al. (2020) in the context of three industries in Norway. In this study, the quality of communication was found to be the most important collaboration factor in reducing transaction costs of projects.

The findings largely support prior research's propositions regarding project organization. For example, the notion of the significant impact of the project leader's personal commitment and true leadership on the project success is in line with Ericksen and Dyer's (2004) results that emphasize how important it is for the team leader to receive high-quality outputs through quick mobilization of work and personnel socialization. Furthermore, our empirical findings support the notion that trust between parties is a necessary condition for the emergence of collaboration (Zerjav, 2015). Overall, the importance of developing trust and commitment through relationship and identity building efforts in the context of industrial engineering projects was highlighted by the interviewees, confirming prior findings on inter-organizational collaboration particularly in the construction sector (Aaltonen and Turkulainen, 2018; Oraee et al., 2017; Walker et al., 2017). However, in-depth examinations on the mindset and cultural challenges with regard to interorganizational collaboration in industrial engineering projects have been relatively limited in prior research with few exceptions (Aarseth, 2014; Bedwell et al., 2012). Our findings brought up particularly the interesting notion of the critical attitudes of financiers and some suppliers toward collaborative approaches; many of them experienced inter-organizational collaboration as highly challenging partly because of the potential uncertainties of the novel approaches. It was clear that inter-organizational collaboration practices such as the bonus model or co-location practices were experienced as a risk by some of the actors resonating with the mindset challenges. It seemed that for these actors it was natural to rely on the old practices and traditional taken-for-granted values and norms of behavior, emphasizing controversies and conflicts, because that was simply the way of thinking the actors were used to. 
With regard to the process components, the importance of developing and maintaining investors' collaborative project management skills over the lifecycle of investment projects was highlighted in the interviews. Developing and mobilizing the skills swiftly was very evident, considering this interviewee's remark: "If you think about us as an investor, or various other industrial companies as well, large investments come our way maybe once in a decade ... and the world changes in a decade." Another important factor related to project organization that was emphasized involved building capacities for project network through partnering and committing to strong partners over the lifecycle of projects. Consequently, both the owner's collaboration capabilities as well as potential for mobilizing capable partners were addressed, which highlights the need to define roles and processes for collaboration (Dietrich et al., 2010) as well as to ensure owner's organizational efficiency and collaboration orientation (Haaskjold et al., 2020).Concerning project tools, the interviewees expressed interesting views on having good experiences of visualizing building site rules in the context of multi-national industrial engineering projects:

We had 17 nations in the building site, so the language barrier was real.

\begin{abstract}
There were so many rules in the building site, and considering the language barrier, we had large crossed over pictures indicating what should not be done, and those we handed around, if problems arose, we were strict ... about bonuses ... everyone knew what happened if those [rules] were not followed.
\end{abstract}

Furthermore, sometimes visualizing and communicating the project rules proved not to be effective enough, and, therefore, project organizations were obliged to collaboratively create new rules; this sort of flexibility eventually seemed to support the success of the whole project. Prior literature on interorganizational collaboration tools has primarily focused on co-locational set-ups, such as Big Rooms (Gustavsson and Gohary, 2012; Walker et al., 2017), but the role of visual management in order to enhance project control and performance has attracted significantly less attention.

Finally, the review on prior literature showed that research on inter-organizational collaboration has paid limited attention to project products. The results of this study reveal and determine new insights and a few preconditions for inter-organizational collaboration respecting project products. Pilot testing of process technology and possibility of novel processes in a factory setting are important factors in creating a successful industrial engineering project. Further, the valuable investment received through inter-organizational collaboration creates a solid precondition for building a successful end product and an industrial engineering facility. According to an interviewee, "with the traditional project management model, the investor only knows the minimum investment price for the facility, and what it maximally may cost [due to extra work], no one knows. Project alliance eliminated this problem." Through collaboration, investors have a continuous visibility of the value of their investment returns and can therefore create more valuable project products, which also helps to minimize risks in industrial engineering projects.

\title{
6. Conclusions
}

In conclusion, this study examined the challenges of and preconditions for inter-organizational collaboration in an industrial engineering project setting. The study did not pay special attention to the contractual relationships among the project participants, since the contractual basis does not directly affect project performance; instead, the quality and content of inter-organizational collaboration was focused at as it positively affects performance (Suprapto et al., 2016). Therefore, we tried to explore and elaborate generally applicable challenges and preconditions related to inter-organizational collaboration in the context of industrial engineering projects. This study advances our understanding of inter-organizational collaboration in industrial engineering projects, which, as a context for collaboration, have received clearly less attention in prior literature when compared to the construction and infrastructure projects (Walker et al., 2017). 
Furthermore, the adoption of project life-cycle perspective on the exploration of challenges and preconditions for inter-organizational collaboration provides novel insights regarding how interorganizational collaboration may develop and should be fostered over the lifecycle of projects. Research on the dynamics of inter-organizational collaboration in temporary contexts has been particularly called for (van Marrewijk et al., 2016).

The first research question (RQ1) was centered on defining how inter-organizational collaboration in industrial engineering projects is defined in literature. To answer this research question a theoretical framework of inter-organizational collaboration was elaborated and classified around project systems (Browning et al., 2006). In addition to providing a structured perspective on inter-organizational collaboration, the classification also revealed the project product as a theme that may benefit from further research with regard to inter-organizational collaboration. Researching how the interplay of the actual project product and the organizing of inter-organizational collaboration may unfold would be a highly fruitful avenue for future research.

The second research question (RQ2) aimed to understand the challenges of inter-organizational collaboration. By exploring and elaborating the challenges of inter-organizational collaboration in different phases of the project, the study provides a more nuanced understanding of the dynamics of factors that may hinder collaboration in different stages of industrial engineering projects. The adoption of a project life-cycle perspective, instead of a static view which is dominantly adopted in prior studies, is highly relevant for managers: through this approach they can make better collaboration related decisions taking the contingencies of the different phases into account. Prior research has also asserted that much emphasis needs to be put on overcoming inter-organizational collaboration challenges during the earliest stages for projects (Aapaoja et al. 2013). This notion was also made in our study, and particularly the role of the investor's capabilities and organizational culture was emphasized. Consequently, the early events may have significant effects on the later events with re-enforcing dynamics.

The third research question (RQ3) addressed the pre-conditions for inter-organizational collaboration. Some authors (e.g., Merrow, 2011) have critiqued collaborative arrangements in industrial engineering project settings. However, our empirical data suggest that collaboration challenges can be overcome when they are managed effectively. Our empirical analysis revealed various preconditions for inter-organizational collaboration, which have received limited attention in the context of industrial engineering projects (Haaskjold et al., 2020). Furthermore, the elaboration and categorization of the preconditions of interorganizational collaboration provide a more holistic and systematic understanding of factors that may facilitate collaboration in industrial engineering project settings. Of importance are the focus on collaborative project practices in the contract preparation phase, early engagement of subcontractors for the development of joint goals, reward-schemes, focus on the establishment of culture that facilitates inter-organizational collaboration, implementation of various integration and coordination tools and practices, and focus on the value for the investors. To synthesize, this study develops a novel understanding of the contested theme of inter-organizational collaboration particularly in industrial engineering projects.

Considering the practical implications of this study, practitioners may use the results as guidelines, when they consider whether to use collaborative practices in their projects. The listed challenges and preconditions for collaboration are not by default reliant on the contractual terms and conditions rather, our findings suggest that inter-organizational collaboration can be developed in projects, regardless of the contractual requirements of project participants. The results also provide instructions for decision-makers on the important inter-organization collaboration related issues, which need to be paid attention to in the different stages of industrial engineering projects. Most importantly, guidelines for different key actors can be derived from the analysis. Investors should devote significant time and efforts on building collaborative competences and making decisions on the level of collaboration in Gate 0 . In pre-engineering state it is also important that the subcontractors engage themselves in collaborative practices and build commitment toward common goals. Joint collaborative planning and establishment of joint reward models is needed. The commitment of 
most significant subcontractors should be secured already at this stage instead of the more traditional approach, where the key suppliers are selected later. In addition, the funding bodies and financiers should be informed clearly about the benefits of collaborative approaches in industrial engineering projects. Even though such approaches demand more front-end loading and efforts they may help to secure better returns and value in the long run.

This research provides a better understanding of the conditions under which collaborative practices can be applied to industrial engineering projects. However, this research has also several limitations. The empirical data are mostly based on interviews, which were conducted retrospectively, based on the interviewees' memories of the events. Adding longitudinal or observational elements to the qualitative study can improve the reliability of the results. In addition, the use of only qualitative data poses naturally limitations. Further research that would utilize mixed-methods approaches is therefore welcomed as it would enable to build a more complete understanding of the preconditions and challenges. Furthermore, the generalizability of the results may be difficult, mainly because the empirical results were gathered in a single country and in a single project network.

Further research is required from various viewpoints and taking into account the limitations. Understanding of how the identified preconditions for inter-organizational collaboration influence various industrial project cases in practice would be of value. Empirical studies would also be needed on the performance of projects that succeed in achieving the required preconditions for collaboration. It would also be important to understand if some preconditions are more significant for collaboration and project success than others. The results also highlighted the role of project product in the creation of collaborative schemes. Studies that would focus on the interaction of collaboration decisions and the actual project product are therefore welcomed. This study also paved the avenue for further studies examining the dynamics of interorganizational collaboration over the project-lifecycle. Based on the results it seems evident that the early project events may have significant implications for forthcoming possibilities of inter-organizational collaboration. Studying the path dependent processes with regard to inter-organizational collaboration may be one avenue to take this research forward. Here also systems dynamics modeling may offer possibilities for understanding the reinforcing dynamics of the made decisions on the collaborative practices better. Interestingly also the suspicious attitudes and mindset of financiers toward inter-organizational collaboration and joint reward schemes were brought up in the study. Adopting different organizational theory perspectives, such as institutional theory, may help to understand and explain this phenomenon in a more in-depth manner. Finally, exploring the possibilities for collaborative working and dialogue with the regulatory agencies and permission authorities, whose role is crucial in the early stages of projects, would offer fruitful possibilities for further research.

\section{References}

Aagaard, A., Eskerod, P., and Madsen, E.S. (2014), "Key drivers for informal project coordination among subcontractors: a case study of the offshore wind energy sector", International Journal of Managing Projects in Business, Vol. 8 No. 2, pp. 222-240.

Aarseth, W. (2014). Project Management - A New Mindset for Success: Collaborative Business and Global Mindset. Fagbokforlaget, 166 p.

Aaltonen, K. and Turkulainen, V. (2018), "Creating relational capital through socialization in project alliances", International Journal of Operations and Production Management, Vol. 38 No. 6, pp. 1387-1421, https://doi.org/http://dx.doi.org/10.1108/MRR-09-2015-0216

Aapaoja, A., Haapasalo, H. and Söderström, P. (2013), "Early stakeholder involvement in the project definition phase: case renovation", ISRN Industrial Engineering, 2013, 1-14, https://doi.org/10.1155/2013/953915

Aapaoja, A., Herrala, M., Pekuri, A. and Haapasalo, H. (2013), "The characteristics of and cornerstones for 
creating integrated teams", International Journal of Managing Projects in Business, Vol. 6 No. 4, pp. 695-713.

Aarseth, W., Andersen, B., Ahola, T. and Jergeas, G. (2012), "Practical difficulties encountered in attempting to implement a partnering approach", International Journal of Managing Projects in Business, Vol. 5 No. 2, pp. 266-284.

Aarseth, W. and Sorhaug, T. (2009), "Improving business performance in multi-company projects through cooperative power", International Journal of Business Performance Management, Vol. 11 No. 4, pp. 364-382. https://doi.org/10.1504/IJBPM.2009.030955

Ahola, T., Ruuska, I., Artto, K. and Kujala, J. (2014), "What is project governance and what are its origins?", International Journal of Project Management, Vol. 32 No. 8, pp. 1321-1332, https://doi.org/10.1016/j.ijproman.2013.09.005

Artto, K., Eloranta, K. and Kujala, J. (2008), "Subcontractors' business relationships as risk sources in project networks", International Journal of Managing Projects in Business, Vol. 1 No. 1, pp. 88-105. https://doi.org/10.1108/17538370810846432

Bedwell, W. L., Wildman, J. L., DiazGranados, D., Salazar, M., Kramer, W. S. and Salas, E. (2012), "Collaboration at work: An integrative multilevel conceptualization", Human Resource Management Review, Vol. 22 No. 2, pp. 128-145, doi:10.1016/j.hrmr.2011.11.007

Børve, S., Rolstadas, A., Andersen B. and Aarseth, W. (2017), "Defining project partnering", International Journal of Managing Projects in Business, Vol. 10, No. 4, pp. 666-699, DOI 10.1108/IJMPB-10-2016-0076

Browning, T.R., Fricke, E. and Negele, H. (2006), "Key concepts in modeling product development processes", Systems Engineering, Vol. 9 No. 2, pp. 104-128, https://doi.org/10.1002/sys.20047

Chakkol, M., Selviaridis, K. and Finne, M. (2018), "The governance of collaboration in complex projects", International Journal of Operations and Production Management, Vol. 38 No. 4, pp. 997-1019, https://doi.org /10.1108/IJOPM-11-2017-0717

Chen, L., Manley, K., Lewis, J., Helfer, F. and Widen, K. (2018), "Procurement and governance choices for collaborative infrastructure projects", Journal of Construction Engineering and Management, Vol. 144 No. 8, pp. 1-10, https://doi.org/10.1061/(ASCE)CO.1943-7862.0001525

Chiocchio, F., Grenier, S., O'Neill, T. A., Savaria, K. and Willms, D. J. (2012). "The effects of collaboration on performance: A multilevel validation in project teams", International Journal of Project Organisation and Management, Vol. 4 No. 1, pp. 1-37, doi:10.1504/IJPOM.2012.045362

Confederation of Finnish Industries. (2018). Investment Indicators.

DeFillippi, R. and Sydow, J. (2016), "Project networks: governance choices and paradoxical tensions", Project Management Journal, Vol. 47 No. 5, pp. 6-17, https://doi.org/10.1177/875697281604700502

Dietrich, P., Eskerod, P., Dalcher, D. and Sandhawalia, B. (2010), "The dynamics of collaboration in multipartner projects", Project Management Journal, Vol. 41 No. 4, pp. 59-78, https://doi.org/10.1002/pmj

Ericksen, J. and Dyer, L. (2004), "Right from the start: exploring the effects of early team events on subsequent project team development and performance", Administrative Science Quarterly, Vol. 49 No. 3, pp. 438-471, https://doi.org/10.2307/4131442

Grabher, G. (2002), "Cool projects, boring institutions: temporary collaboration in social context", Regional Studies, Vol. 36 No. 3, pp. 205-214, https://doi.org/10.1080/00343400220122025

Gustavsson, T.K. and Gohary, H. (2012), "Boundary action in construction projects: new collaborative project 
practices", International Journal of Managing Projects in Business, Vol. 5 No. 3, pp. 364-376.

Haaskjold, H., Andersen B. and Aarseth W. (2020), "Factors affecting transaction costs and collaboration in projects", International Journal of Managing Projects in Business, Vol. 13, No. 1, pp. $197-230$. https://doi.org/10.1108/IJMPB-09-2018-0197

Hsieh, H.-F. and Shannon, S.E. (2005), "Three Approaches to Qualitative Content Analysis", Qualitative Health Research, Vol. 15 No. 9, pp. 1277-1288. https://doi.org/10.1177/1049732305276687

Ketokivi, M. and Choi, T. (2014), "Renaissance of case research as a scientific method", Journal of Operations Management, Vol. 32 No. 5, pp. 232-240, https://doi.org/10.1016/j.jom.2014.03.004

Lahdenperä, P. (2012), "Making sense of the multi-party contractual arrangements of project partnering, project alliancing and integrated project delivery", Construction Management and Economics, Vol. 30 No. 1, pp. 57-79, https://doi.org/10.1080/01446193.2011.648947

Lahdenperä, P. (2017), "Towards a coherent theory of project alliancing: discovering the system's complex mechanisms yielding value for money", Construction Economics and Buildings, Vol. 17 No. 2, pp. 41-61, https://doi.org/10.5130/AJCEB.v17i2.5292

Ligthart, R., Oerlemans, L. and Noorderhaven, N. (2016), "In the shadows of time: a case study of flexibility behaviors in an interorganizational project", Organization Studies, Vol. 37 No. 12, pp. 1721-1743, https://doi.org/10.1177/0170840616655487

Lloyd-Walker, B.M., Mills, A.J. and Walker, D.H.T. (2014), "Enabling construction innovation: the role of a noblame culture as a collaboration behavioural driver in project alliances", Construction Management and Economics, Vol. 32 No. 3, pp. 229-245, https://doi.org/10.1080/01446193.2014.892629

Nevstad, K., Børve, S., Karlsen A. and Aarseth W. (2018), "Understanding how to succeed with project partnering", International Journal of Managing Projects in Business, Vol. 11 No. 4, pp. 1044-1065, https://doi.org/10.1108/IJMPB-07-2017-0085

van Marrewijk, A., Ybema, S., Smits, K., Clegg, S. and Pitsis, T. (2016), "Clash of the titans: Temporal organizing and collaborative dynamics in the Panama Canal Megaproject, Organization Studies, Vol. 37 No. 12, pp. 1745-1769, https://doi.org/10.1177/0170840616655489

Manley, K. and Chen, L. (2017), "Collaborative learning to improve the governance and performance of infrastructure projects in the construction sector", Journal of Management in Engineering, Vol. 33 No. 5, pp. 1-14.

Manu, E., Ankrah, N., Chinyio, E. and Proverbs, D. (2015), "Trust influencing factors in main contractor and subcontractor relationships during projects", International Journal of Project Management, Vol. 33 No. 7, pp. 1495-1508, https://doi.org/10.1016/j.ijproman.2015.06.006

Martinsuo, M. and Ahola, T. (2010), "Supplier integration in complex delivery projects: comparison between different buyer-supplier relationships", International Journal of Project Management, Vol. 28 No. 2, pp. 107-116, https://doi.org/10.1016/j.ijproman.2009.09.004

Merrow, E.W. (2011), Industrial Megaprojects: Concepts, Strategies and Practices for Success. John Wiley \& Sons, Inc., Hoboken, New Jersey.

Mesa, H.A., Molenaar, K.R. and Alarcón, L.F. (2016), "Exploring performance of the integrated project delivery process on complex building projects", International Journal of Project Management, Vol. 34 No. 7, pp. 1089-1101,https://doi.org/10.1016/j.ijproman.2016.05.007.

Miller, R. and Lessard, D.R. (2000), The Strategic Management of Large Engineering Projects: Shaping Institutions, Risks, and Governance. Massachusetts Institute of Technology. 
Oliveira, N. and Lumineau, F. (2017), "How coordination trajectories influence the performance of interorganizational project networks", Organization Science, (October), 1-32, https://doi.org/10.1287/orsc.2017.1151

Oraee, M., Hosseini, M.R., Papadonikolaki, E., Palliyaguru, R. and Arashpour, M. (2017), Collaboration in BIMbased construction networks: a bibliometric-qualitative literature review", International Journal of Project Management, Vol. 35 No. 7, pp. 1288-1301, https://doi.org/10.1016/j.ijproman.2017.07.001

Ruuska, I., Ahola, T., Artto, K., Locatelli, G. and Mancini, M. (2011), "A new governance approach for multifirm projects: lessons from Olkiluoto 3 and Flamanville 3 nuclear power plant projects", International Journal of Project Management, Vol. 29 No. 6, pp. 647-660, https://doi.org/10.1016/j.jproman.2010.10.001

Samset, K. and Volden, G.H. (2016), "Front-end definition of projects: ten paradoxes and some reflections regarding project management and project governance", International Journal of Project Management, Vol. 34 No. 2, pp. 297-313, https://doi.org/10.1016/j.ijproman.2015.01.014

Seale, C., Gobo, G., Gubrium, J.F. and Silverman, D. (2004), Qualitative Research Practice. Sage Publications Ltd., London.

Suprapto, M., Bakker, H.L.M., Mooi, H.G. and Hertogh, M.J.C.M. (2016), "How do contract types and incentives matter to project performance?", International Journal of Project Management, Vol. 34 No. 6, pp. 1071-1087, https://doi.org/10.1016/j.ijproman.2015.08.003

Suprapto, M., Bakker, H.L.M., Mooi, H.G. and Moree, W. (2015), "Sorting out the essence of ownercontractor collaboration in capital project delivery", International Journal of Project Management, Vol. 33 No. 3, pp. 664-683, https://doi.org/10.1016/j.ijproman.2014.05.001

Teerikangas, S. and Geraldi, J. (2015), "Integration in the study of organizations-a lack of integration?", in 75th Annual Meeting of the Academy of Management, pp. 1-5.

Walker, D.H.T., Davis, P.R. and Stevenson, A. (2017), "Coping with uncertainty and ambiguity through team collaboration in infrastructure projects", International Journal of Project Management, Vol. 35 No. 2, pp. 180-190, https://doi.org/10.1016/j.ijproman.2016.11.001

Walker, D.H.T. and Lloyd-Walker, B.M. (2015), Collaborative Project Procurement Arrangements. Project Management Institute PMI.

Williams, T. and Samset, K. (2010), "Issues in front-end decision making on projects", Project Management Journal, Vol. 41 No. 2, pp. 38-49, https://doi.org/10.1002/pmj

Yin, R.K. (2003), Case Study Research. Design and Methods, 3rd ed. Sage Publications Inc.

Zerjav, V. (2015), "Design boundary dynamics in infrastructure projects: issues of resource allocation, path dependency and problem-solving", International Journal of Project Management, Vol. 33 No. 8, pp. 1768-1779, https://doi.org/10.1016/j.ijproman.2015.09.009 


\begin{tabular}{|c|c|c|c|c|c|c|}
\hline Source & $\begin{array}{l}\text { Project } \\
\text { collaboration } \\
\text { focus }\end{array}$ & Goal(s) & Organization & Process(es) & Tool(s) & Product(s) \\
\hline (Walker et al., 2017) & $\begin{array}{l}\text { The ability of } \\
\text { collaboration to } \\
\text { enhance coping } \\
\text { with uncertainty } \\
\text { and ambiguity }\end{array}$ & $\begin{array}{l}\text { An integrated risk } \\
\text { mitigation strategy } \\
\text { Behavioral } \\
\text { characteristics and } \\
\text { normative practice: } \\
\text { open book auditing } \\
\text { Consensus decision- } \\
\text { making } \\
\text { Incentivization scheme } \\
\text { for gain and pain } \\
\text { sharing } \\
\text { Mutual dependency and } \\
\text { accountability }\end{array}$ & $\begin{array}{l}\text { Behavioral } \\
\text { characteristics and } \\
\text { normative practice: } \\
\text { authentic leadership, } \\
\text { trust-control balance, } \\
\text { best-for-the-project } \\
\text { mindset and culture, } \\
\text { no-blame culture }\end{array}$ & $\begin{array}{l}\text { Substantial co- } \\
\text { location: } \\
\text { hierarchical } \\
\text { integration }\end{array}$ & $\begin{array}{l}\text { Substantial } \\
\text { colocation: } \\
\text { physical/virtual } \\
\text { space }\end{array}$ & \\
\hline (Dietrich et al., 2010) & $\begin{array}{l}\text { Collaboration } \\
\text { antecedents }\end{array}$ & $\begin{array}{l}\text { Alignment of incentives } \\
\text { Goal congruence and } \\
\text { alignment of goals }\end{array}$ & $\begin{array}{l}\text { Trust between actors } \\
\text { Commitment to } \\
\text { project } \\
\text { Conflict resolution } \\
\text { Expectations } \\
\text { fulfillment }\end{array}$ & $\begin{array}{l}\text { Roles and } \\
\text { processes for } \\
\text { collaboration }\end{array}$ & $\begin{array}{l}\text { Physical and } \\
\text { cultural proximity }\end{array}$ & \\
\hline $\begin{array}{l}\text { (Gustavsson and } \\
\text { Gohary, 2012) }\end{array}$ & $\begin{array}{l}\text { Boundary actions } \\
\text { in collaborative } \\
\text { project practices }\end{array}$ & & $\begin{array}{l}\text { Professional boundary } \\
\text { action: combining } \\
\text { competences in design } \\
\text { phase }\end{array}$ & $\begin{array}{l}\text { Stakeholder } \\
\text { boundary action: } \\
\text { changing } \\
\text { operational roles } \\
\text { and } \\
\text { responsibilities }\end{array}$ & $\begin{array}{l}\text { Geographical } \\
\text { boundary action: } \\
\text { physical co- } \\
\text { location }\end{array}$ & \\
\hline
\end{tabular}




\begin{tabular}{|c|c|c|c|c|c|}
\hline (Suprapto et al., 2015) & $\begin{array}{l}\text { Components of } \\
\text { collaborative } \\
\text { working } \\
\text { relationship } \\
\text { between project } \\
\text { parties }\end{array}$ & Contract & $\begin{array}{l}\text { Team-working } \\
\text { Relational attitudes } \\
\text { Capability }\end{array}$ & $\begin{array}{l}\text { Team integration } \\
\text { Joint working }\end{array}$ & \\
\hline (Chen et al., 2018) & $\begin{array}{l}\text { Contractual and } \\
\text { Non-contractual } \\
\text { governance in } \\
\text { collaborative } \\
\text { projects }\end{array}$ & $\begin{array}{l}\text { Risk and reward sharing } \\
\text { Service provider's } \\
\text { responsibility on rising } \\
\text { costs }\end{array}$ & $\begin{array}{l}\text { Leadership } \\
\text { Team workshops } \\
\text { Relationship } \\
\text { management }\end{array}$ & $\begin{array}{l}\text { Design } \\
\text { integration }\end{array}$ & $\begin{array}{l}\text { Communication } \\
\text { systems }\end{array}$ \\
\hline $\begin{array}{l}\text { (Aaltonen and } \\
\text { Turkulainen, 2018) }\end{array}$ & $\begin{array}{l}\text { Inter- } \\
\text { organizational } \\
\text { collaborative } \\
\text { practices }\end{array}$ & 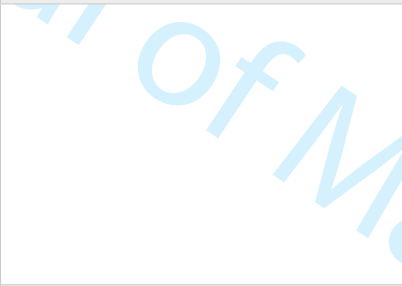 & $\begin{array}{l}\text { Workshops } \\
\text { Relationship programs } \\
\text { Joint training }\end{array}$ & & 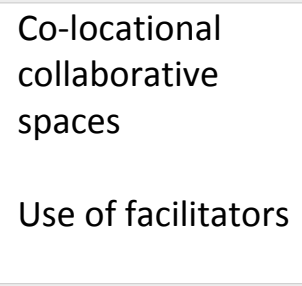 \\
\hline (Lahdenperä, 2012) & $\begin{array}{l}\text { Collaborative } \\
\text { project } \\
\text { arrangements; key } \\
\text { features }\end{array}$ & Commercial unity & $\begin{array}{l}\text { Team formation } \\
\text { Operational } \\
\text { procedures } \\
\text { Cooperative culture }\end{array}$ & $\begin{array}{l}\text { Planning } \\
\text { emphasis } \\
\text { Administrational } \\
\text { consistency }\end{array}$ & $\begin{array}{l}\text { Teamwork } \\
\text { premises }\end{array}$ \\
\hline (Oraee et al., 2017) & $\begin{array}{l}\text { Collaboration in } \\
\text { BIM-based } \\
\text { construction } \\
\text { networks: } \\
\text { collaboration } \\
\text { antecedents }\end{array}$ & $\begin{array}{l}\text { Context: legal } \\
\text { framework }\end{array}$ & $\begin{array}{l}\text { Context: } \\
\text { organizational } \\
\text { environment, } \\
\text { structure and culture, } \\
\text { communication styles, } \\
\text { skills and knowledge } \\
\text { Team: knowledge } \\
\text { sharing }\end{array}$ & $\begin{array}{l}\text { Tasks } \\
\text { Team: roles and } \\
\text { responsibilities; } \\
\text { relationships }\end{array}$ & $\begin{array}{l}\text { Process: tools and } \\
\text { software; } \\
\text { network-based } \\
\text { computing }\end{array}$ \\
\hline
\end{tabular}


Actor: skills,

knowledge,

experience

Table I. Components of inter-organizational project collaboration in project management literature 
11

12

14

15

16

17

18

19

20

21

22

23

24

25

26

27

29

30

31

32

33

34

35

36

37

38

39

40

41
42

.

44

45 


\begin{tabular}{|c|c|c|c|c|}
\hline COMPANIES & $\begin{array}{l}\text { NUMBER OF } \\
\text { INTERVIEWEES }\end{array}$ & $\begin{array}{l}\text { INTERVIEWEE } \\
\text { ROLES }\end{array}$ & $\begin{array}{l}\text { MINUTES AND } \\
\text { PAGES }\end{array}$ & $\begin{array}{l}\text { SUPPORTING } \\
\text { MATERIAL }\end{array}$ \\
\hline OWNER & 1 & $\begin{array}{l}\text { Managing Director } \\
\text { (CEO) }\end{array}$ & $\begin{array}{l}162 \text { min, } 25 \\
\text { pages } \\
\text { “ }\end{array}$ & $\begin{array}{l}\text { Newspaper } \\
\text { articles, } \\
\text { workshop } \\
\text { materials, } \\
\text { company } \\
\text { presentations }\end{array}$ \\
\hline $\begin{array}{l}\text { MAIN ALLIANCE } \\
\text { CONTACTOR }\end{array}$ & 4 & $\begin{array}{l}\text { Alliance Steering } \\
\text { Group Member, } \\
\text { Project Manager, } \\
\text { Worksite Manager, } \\
\text { Project Manager }\end{array}$ & $\begin{array}{l}151 \mathrm{~min}, 26 \\
\text { pages }\end{array}$ & \\
\hline $\begin{array}{l}\text { NON-ALLIANCE } \\
\text { SUBCONTRACTOR }\end{array}$ & 2 & $\begin{array}{l}\text { Director, Project } \\
\text { Manager }\end{array}$ & $\begin{array}{l}180 \text { min, } 24 \\
\text { pages }\end{array}$ & \\
\hline INVESTOR B & 1 & CEO & $\begin{array}{l}143 \min , 21 \\
\text { pages }\end{array}$ & $\begin{array}{l}\text { Newspaper } \\
\text { articles }\end{array}$ \\
\hline CONTRACTOR B & 1 & Project Manager & $\begin{array}{l}105 \min , 20 \\
\text { pages }\end{array}$ & $\begin{array}{l}\text { Workshop } \\
\text { materials }\end{array}$ \\
\hline $\begin{array}{l}\text { FINANCING } \\
\text { BODY/ORGANIZATION }\end{array}$ & 1 & CEO & & Company slides \\
\hline
\end{tabular}


N-TIER

SUBCONTRACTOR A

INDUSTRIAL SERVICE

PROVIDER

CONSULTANT

PROJECT

MANAGEMENT

TRAINING AND

CONSULTING

N-TIER

SUBCONTRACTOR B

$\begin{array}{ll}\begin{array}{l}\text { CEO, Project } \\ \text { Engineer, } \\ \text { Development } \\ \text { Manager }\end{array} & \begin{array}{l}158 \mathrm{~min}, 25 \\ \text { pages }\end{array} \\ \begin{array}{l}\text { Regional Manager x } \\ \text { 2, Project } \\ \text { Development } \\ \text { Manager, Director }\end{array} & \begin{array}{l}160 \mathrm{~min}, 32 \\ \text { pages }\end{array} \\ & \\ \begin{array}{l}\text { Project Manager x } \\ \text { 2, Partner }\end{array} & \\ & \begin{array}{l}117 \text { min, 16 } \\ \text { pages }\end{array} \\ & \\ \text { Coach } & \\ & 133 \text { min, 15 } \\ & \text { pages }\end{array}$

1

CEO

Company slides

3

1

pages

Table II. Company characteristics and data collection tools (companies and interviewees) 


\title{
Project phase Key challenges for collaboration
}

\author{
GATEO: Difficulties in gaining investors' internal approval of collaborative project practices \\ decision on \\ the level of \\ collaboration \\ Investors' organizational culture, which may not support collaborative practices \\ Lack of investors' knowledge of collaborative project management best practices \\ Investors' goals for collaboration are unclear \\ Collaborative contract creation and alliance formation take more time than in a \\ conventional project. \\ Shared IPRs on collaborative solutions \\ FEL2: pre- \\ A large number of decisions are locked before the development phase begins. \\ engineering \\ Project organizations keeping up the traditional culture \\ Common goals for design work are not agreed unanimously, and goals differ between \\ designers and process equipment manufacturers, for example. \\ Focus is on the investment project rather than on the ramp-up or the lifecycle of the \\ industrial facility. \\ GATE1: Challenges of securing funding for the project pre-engineering and design phase \\ investment \\ Breaks for funding during pre-engineering may lead to missing experts from the project \\ team \\ Difficulties in finding multiple investors \\ Political environment related to the investment \\ FEL3: basic \\ Challenges of receiving design basic information \\ engineering \\ Decisions on process equipment and other suppliers are received too late \\ Challenges of leadership and lack of team building efforts \\ Big Room activities are not fostered and managed well enough \\ Key personnel do not have enough resources to participate full-time in the Big Room \\ activities \\ Ensuring the availability of key personnel resources and challenges of recruitment \\ Incentives are not tied well enough to the project targets \\ Collaboration capabilities of supplier organizations vary considerably \\ Challenges of and coordinating design solutions between various suppliers and \\ communicating the changes properly across different suppliers
}


Table III. Key challenges of collaboration in different project phases 


\section{Project system Key preconditions}

Goals

cisions on collaborative project practices are made before signing contracts.

Targets on and responsibilities for collaboration

Collaborative bonus model on contracts

Communicating the bonus model and measures

A model that introduces collaborative elements for subcontractors

Investors' collaborative project management skills and commitment are properly maintained.

Partnering early and over projects

Each organization's collaborative capabilities

\section{Related project practices}

Decisions on collaborative practices are made before signing contracts.

Clear targets and responsibilities for collaboration are defined.

Funding body pays attention to which party in essence leads the project and holds responsibility

Collaborative bonus model is entered into the contracts, including required levels of physical presence

Establishing a collaborative bonus model on contract with respective unequivocal measures

Communicating the bonus model and respective measures to individual organizations

Establishing clear, communicated, and visualized project targets Target hour contracting introduces collaborative elements for $\mathrm{N}$-tier subcontractors

Reward system, also for subcontractors, tied to project milestones Investors' collaborative project management skills are properly maintained over time and projects

Securing investors' internal organizational commitment to collaborative practices

Contacting potential project partners early

Investors' commitment to strong partners over projects

Building technical capabilities of project network through partnering

Prior ties between project partners

Project partners' ability to collaborate and operate in a collaborative manner 
Successful recruitment

Education

Collaboration over disciplines

True leadership and personal commitment of project manager

Project spirit, trust, and personal relationships

\section{Processes}

Required time period available for development phase

Enabling decision-making before final investment

Early integration and involvement

Managing innovation process with rewards
Willingness to collaboratively solve technical problems to optimize the whole production line

Staff availability in the market and ability to recruit staff

Project personnel have a good professional reputation as leading experts in the field

Establishing excessive education scheme on collaborative project practices

Early collaboration between process equipment suppliers, construction contractors, and designers

Establishing true leadership, fostering positive attitude through individual commitment and personal presence of the project manager

Building trust through close cooperation and relationship building

Building project spirit and trust through well-functioning personal relationships

Building site kick-offs for project spirit building

There is a required time period available to execute the development phase

Enabling project decision-making before final decision on investment

Not building excessively heavy tendering processes

Early involvement of funding bodies

\section{Early involvement of low-tier subcontractors}

Early integration of process equipment suppliers, construction contractors, and designers

Managing and continuously improving innovation process; fostering all site personnel to use it by rewards 
Tools

One document management system

Regular, face-to-face meetings

Last planner for work planning and scheduling

Big Room backed up by each organizational support

Building site rules, visualized and communicated

\section{Continuous improvement}

Products

Value for investors

Pilot testing of process technology

Front-end loading
Determining and allowing only one document management system

Allowing only electric documentation

Regular, face-to-face meetings fostering collaborative problem-

solving

Direct collaboration and contact interface between project partners and subcontractors

Last Planner system for collaborative work planning and scheduling

Big Room for a limited number of participants, bouncing ideas,

backed up by organizational support for rapid assessments and

calculations

Building site rules, communicated and visualized

Readiness to change the rules whenever necessary

Managed self-reflection sessions and continuous improvement

Receiving design basic information from process

machinery suppliers as early as possible

Investors know what exactly they purchase with the money

invested, and what the delivery of industrial engineering facility

includes

Pilot testing for process equipment technology in a factory setting

Well-executed and thorough front-end loading phase

Table IV. Preconditions for inter-organizational collaboration in industrial engineering projects 
Figure 1. Preconditions for collaboration in industrial engineering projects

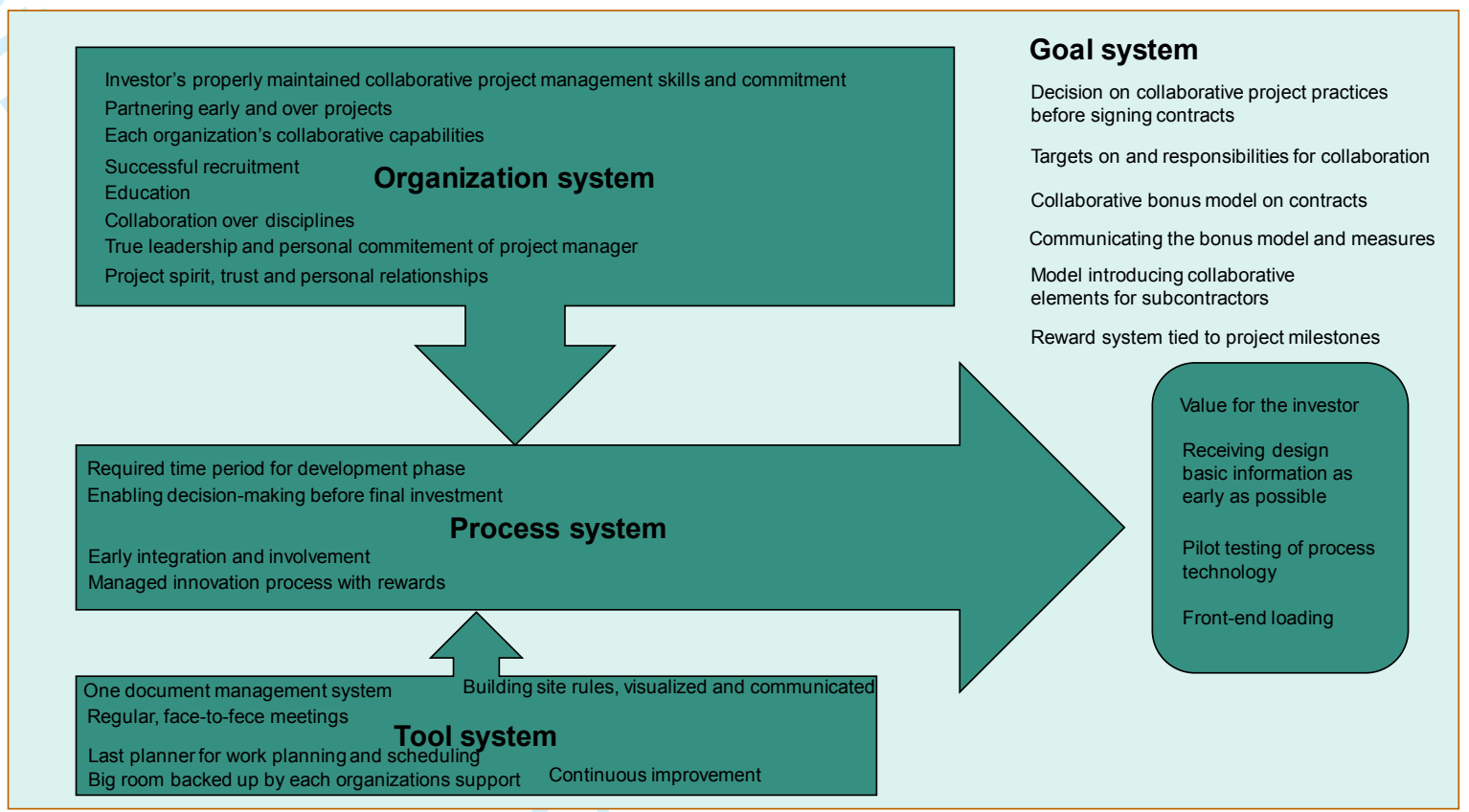

